Jp.jok (Jurnal Pendidikan Jasmani, Olahraga dan Kesehatan)

http://ejurnal.budiutomomalang.ac.id/index.php/jpjok

Doi : $\underline{\text { https://doi.org/10.33503/jp.jok.v5i1.1211 }}$

\title{
Implementation of Fullover Training Towards The Improvement of Badminton Smash Corresponding with The Covid 19 Health Protocol
}

\author{
Irsan Kahar ${ }^{1)}$, Firmansyah Dahlan ${ }^{2)}$, Syahruddin ${ }^{3)}$, Suaib Nur ${ }^{4)}$ \\ Program studi Pedidikan Jasmani \\ Fakultas Keguruan Ilmu dan Pendidikan \\ ${ }^{1,2,4}$ Universitas Muhammadiyah Palopo, Indonesia \\ Fakultas Ilmu Keolahragaan \\ ${ }^{3}$ Universitas Negeri Makassar, Indonesia \\ Email: irsankahar@umpalopo.ac.id, ${ }^{2}$ firmansyahdahlan800@ gmail.com, ${ }^{3}$ syahruddin@unm.ac.id, \\ 논ibnur@umpalopo.ac.id

\section{ABSTRACT}

There are 2 problems which become the urgency in this research; student activity unit for badminton is a new sports medium, thus it needs improvement in training forms, one of the training form is the improvement of smash basic skill. The aims of this rese arch are to discover the influence of fullover training towards badminton smash basic skill, and also applying the research and training process which correspond with Covid 19 health protocol. This research is an experimenttype. Independent variable (badminton smash basic skill) dependent variable (fullover training). Sampling technique used saturated sample wich is all the population of badminton student activity unitat UM Palopo which are 20 atlethes. Test instrument used smash basic skill test. Time andplace corresponded with WFH( work from home), research processes (pre test, treatment, post test) were monitored online through Zoom meeting and UM Palopo Elearning. The results of hypothesis testfound that t-count 3,647 bigger than $t$-table 1,833 at the $5 \%$ significancy or 0,05. according to the hypothesis test, it can be concluded that Fullover training influence the badminton smash basic skill.

Keywords: Fullover Training, Smash, Health Protocol

\section{Implementasi Latihan Fullover terhadap Peningkatan Smash Bulutangkis sesuai Protokol Kesehatan Covid 19 ABSTRAK}

Urgensitas dalam penelitian ini meliputi 2 (dua) dimensi permasalahan yakni Unit Kegiatan Mahasiswa (UKM) Bulutangkis UM Palopo merupakan wahana pembinaan cabang olahraga yang baru dibentuk sehingga membutuhkan pengembangan bentuk latihan, salah satunya peningkatan teknik dasar smash. Kedua Pembinaan cabang olahraga, harus terus dijalankan . Tujuan penelitian, untuk mengetahui pengaruh latihan power otot lengan (Latihan Fullover) terhadap teknik dasar Smash cabang olahraga bulutangkis, serta mengaplikasikan proses penelitian dan latihan yang memenuhi protokol kesehatan Covid-19. Jenis penelitian yang digunakan yaitu eksperimen. Variabel independen (teknik dasar Smash bulutangkis) Variabel dependen (Latihan Fullover) Teknik sampling menggunakan sampel jenuh yaitu menggunakan seluruh populasi UKM Bulutangkis UM Palopo berjumlah 20 atlet. Instrument tes menggunakan Tes Teknik Dasar Smash. Waktu dan tempat penelitian mengacu pada ketentuan WFH (work from home), proses penelitian (Pre test, treatmen, Post test) dipantau secara daring menggunakan aplikasi Zoom meeting dan E-learning UM Palopo. Hasil pengujian hipotesis ditemukan nilai t-hitung 3,647lebih besar darit-tabel 1,833 pada taraf signifikansi 5\% atau 0,05. Berdasarkan hasil pengujian hipotesis tersebut dapat disimpulkanbahwa Latihan Fullover memiliki pengaruhterhadapteknik dasar Smash cabang olahraga bulutangkis .

Kata Kunci: Latihan Fullover, Smash, Protokol Kesehatan

Info Artikel

Dikirim

Diterima

Dipublikasikan
(C)2021IKIP BUDI UTOMOMALANG

P-ISSN 2613-9421

E-ISSN 2654-8003

\footnotetext{
Alamat korespondensi: irsankahar@umpalopo.ac.id 
2 Irsan Kahar ${ }^{1}$, Firmansyah Dahlan ${ }^{2)}$, Syahruddin $^{3)}$ Jp.jok (Jurnal Pendidikan. Jasmani, Olahraga dan Kesehatan). 5(1) $1-10$

\section{PENDAHULUAN}

Urgensitas dalam penelitian ini meliputi 2 (dua) dimensi permasalahan yakni; pertama, Unit Kegiatan Mahasiswa (UKM) Bulutangkis Universitas Muhammadiyah Palopo (UMP) merupakan wahana pembinaan cabang olahraga yang baru dibentuk sehingga membutuhkan pengembangan bentuk latihan, salah satunya peningkatan teknik dasar smash. Kedua Pembinaan cabang olahraga, termasuk cabang olahraga bulutangkis tentunya harus terus dijalankan karena terkait dengan kegiatan Latihan yang harus kontinyu dan berkesinambungan, sehingga dalam situasi pandemik Covid-19 seperti sekarang ini diperlukan bentuk implementasi latihan yang berkesesuaian dengan Protokol Kesehatan.

Dalam upaya pembinaan cabang olahraga bulutangkis tentunya yang awal untuk dikembangkan adalah keterampilan dasar, salah-satunya adalah smash karena sangat signifikan dalam mematikan permainan lawan dan meraih poin.Smash adalah pukulan suttlecock secepat-cepatnya untuk mendapatkan (Rahmat, 2014). Perbedaan yang mencolok antara pukulan lob shuttlecock dan smash shuttlecock, lob diarahkan ke atas sedangkan smash tajam, curam kebawah, dan kecepatan yang tinggi kerena tenaga sepenuhnya berasaldari cambukan pergelangan yang kuat, (Zarwan \& Hardiansyah, 2017).

Smash menjadi pukulan kunci agar mematikan permainan dan pergerakan lawan, lebih lanjut dijelaskan bahwa pukulan lainnya dapat dikatakan tidak berarti apabila tidak dilengkapi kemampuan smash yang maksimal (Aji Prasojo \& Yahya, 2017). Pukulan lainnya umumnya digunakan agar memancing lawan, mengganggu posisi lawan, membuka daerah pertahanan lawan, adapun smash untuk mengakhiri suatu rally pada bidang lapangan permainan lawan, (Taufan, Dewantara, \& Alsaudi, 2016).Smash merupkan modal untuk mendapatkan poin atau angka dan juga mematahkan serangan lawan, (Cendra, 2018).Karakter dari pukulan smash adalah keras dan laju menuju lantai lanpangan lawan. Pukulan smash ini merupakan pukulan keras yang sangat umum dalam permainan bulutangkis, (Tahir, Mentara, \& Sultan Brilin, 2018).

Urgensitas kedua dari dilaksanakannya penelitian ini yakni diharapkan menjadi referensi ilmiah dalam menjalankan penelitian dan latihan pada masa Pandemik Covid-19 yang mengharuskan adanya pembatasan kegiatan tatap 
muka.Wabah Covid-19 saat ini menyebabkan kerugian seperti pelatihan olahraga ditutup untuk mengikuti protokol kesehatan dari pemerintah dan kegiatan latihan dilakukan di rumah masing-masing atau online(Aini \& Kemala, 2020).Lebih lanjut, Aini \& Kemala (2020) Sayangnya di Indonesia kegiatan ini tidak diikuti dengan kesiapan secara menyeluruh baik dari segi kesiapan mental, fisik, sarana dan prasarana individu untuk menghadapi wabah yang menyebar luas ini.

Bentuk pembelajaran daring atau jarak jauh merupakan sebuah inovasi dalam dunia pendidikan dalam menjawab tantangan pandemi Covid-19. Walaupun tidak ada pertemuan langsung antara guru dan siswa, namun kegiatan pembelajaran tetap berjalan dengan dukungan sumber belajar variatif dan inovatif. Dalam pembelajaran daring atau jarak jauh ini, siswa dapat perkomunikasi dengan pendidik atau guru melalui beberapa aplikasi pendukung seperti saluran telepon, short message service, live chat, group chat, video converence dan room video converence (Hidayat, 2020).Berkaitan dengan hal tersebut maka inovasi yang di implementasikan dalam penelitian ini yakni penggunaan media online dalam menjalankan penelitian dan latihan.

Penelitian yang mengimplementasikan media online untuk memperoleh hasil penelitiannya dapat dilihat melalui penelitian, Mahfud \& Gumantan(2020) Penelitian tentang kecemasan mahasiswa selama pandemi covid-19, metode yang digunakan adalah survey (angket) yang disebarke 110 responden. Nugraha, Utama, S, \& Sulaiman(2020)Survei tentang kegiatan olahraga mahasiswa selama masa pandemi covid-19 yang hasilnya menunjukkan mahasiswa tetap melakukan kegiatan olahraga secara rutin meskipun dirumah masing-masing. Kedua penelitian tersebut menggunakan aplikasi online (google form)sehingga penelitian dalam masa pandemi covid-19 dimungkinkan dilaksanakan menggunakan bantuan aplikasi online.

Rujukan penelitian terdahulu yakni, Penelitian tentang pengaruh latihan power otot lengan terhadap kemampuan smash bulutangkis (Peni, Saripin, \& Kristi, 2016), Kesimpulan dari penelitian tersebut memperlihatkan pengaruh yang siginifikan dari latihan power otot lengan terhadap smash bulutangkis. Adapun pembeda dan yang dikembangkan dari penelitian sebelumnya yaitu proses atau metodologinya yakni penelitian terdahulu dilaksanakan secara tatap 
muka dilapangan adapun dalam penelitian ini secara daring (ZoomMeeting) sehingga implementasi latihan berkesesuaian dengan protocol kesehatan dimasa pandemik. Proses penelitian (metodologi) yang diajukan dalam penelitian ini diharapkan dapat menjadi acuan dan contoh untuk pelatih, klub, maupun institusi terkait lainnya, bahwa treatment dalam bentuk latihan dapat dilaksanakan secara daring, namun tentunya harus dengan komitmen yang tinggi oleh semua pihak dan kemampuan pengaplikasian teknologi dalam menunjang aktivitas tersebut. Terkait hasil penelitian, akan dapat memberikan gambaran pengaruh Latihan Fullover terhadap teknik dasar Smash atlet UKM Bulutangkis UM Palopo.

\section{METODE}

Jenis penelitian yang digunakan yaitu eksperimen, tujuan penelitian eksperimen adalah meneliti adanya kemungkinan sebab akibat dari variabel bebas dan variabel terikat (Arikunto, 2014). Variabel independen (teknik dasar Smash cabang olahraga bulutangkis) Variabel dependen (Latihan Fullover) Teknik sampling menggunakan sampel jenuh dengan mengambi seluruh populasi UKM Bulutangkis UM Palopo berjumlah 20 atlet. Instrument tes menggunakan Tes Teknik Dasar Smash yang dikeluarkan (PB. PBSI, 2006). Tempat penelitian mengacu pada ketentuan Bekerja dan Belajar dari rumah (online), selama proses penelitian (Pre test, treatmen, Post test) dipantau dan diawasi menggunakan Zoom meeting dan E-learning (IqraUM Palopo). Teknik analisis data menggunakan Paired Samples Test melalui aplikasi SPSS 22.

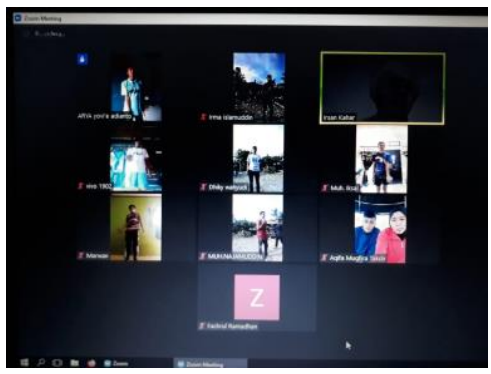

Gambar 1.Kegitan Latihan mengikuti ketentuan WFH 


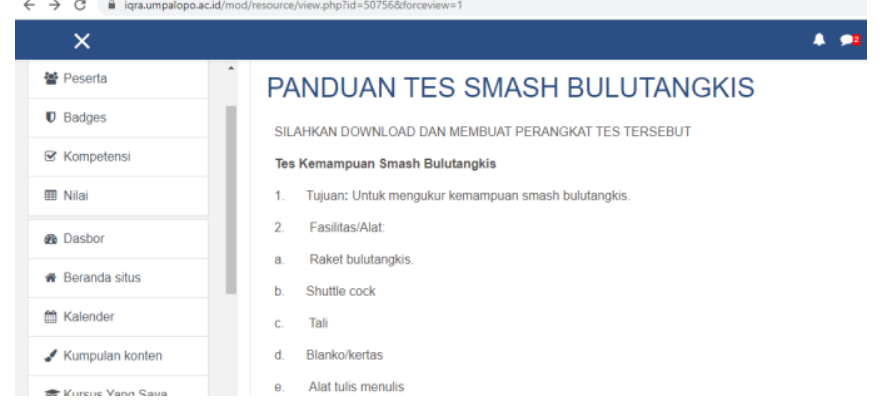

Gambar 2. Panduan Pelaksanaan Tes menggunakan aplikasi E-learning UM Palopo.

\section{HASIL DAN PEMBAHASAN}

\section{HASIL}

Hasil analisis deskriptif ditemukan Pre test latihan Full over untuk nilai Mean 11,10, Standar deviasi 3,479, Range 9, nilai minimal 6, nilai maximal 15, dan nilai sum 111. Untuk Post test latihan Full over untuk nilai Mean 14,40, Standardeviasi 3,098, Range 9, nilai minimal 9, nilai maximal 18, dan nilai sum 114.

Tabel 1.DataAnalisisDeskriptif

\begin{tabular}{lccccccc}
\hline Nilai statistic & $\mathbf{N}$ & Mean & Std & Range & Min & Max & Sum \\
\hline $\begin{array}{c}\text { Pre test latihan } \\
\text { Fullover }\end{array}$ & 10 & 11,10 & 3,479 & 9 & 6 & 15 & 111 \\
\hline $\begin{array}{c}\text { Post test latihan } \\
\text { Fullover }\end{array}$ & 10 & 14,40 & 3,098 & 9 & 9 & 18 & 114 \\
\hline
\end{tabular}

Hasilpengujian hipotesis ditemukannilai t-hitung $>\quad t$-tabel($11,000>1,833)$ padatarafsignifikansi $5 \%$ atau 0,05 .

Tabel 2.Uji Hipotesis

\begin{tabular}{cccc}
\hline t-hitung & t-tabel & $\boldsymbol{\alpha}$ \\
\hline 3,647 & 1,833 & 0,05 \\
\hline
\end{tabular}

\section{PEMBAHASAN}

Hasil pengujian hipotesis ditemukan nilai t-hitung 3,647 lebih besar dari ttabel 1,833 pada taraf signifikansi $5 \%$ atau 0,05 .Hasil penelitian ini yang mengimplementasikan latihan Fullover dalam mengembangkan power otot lengan dan bahu sekiranya sejalan dengan hasil penelitian terdahulu yaitu, Terdapat pengaruh latihan power otot lengan terhadap kemampuan smash bulutangkis dimana $\mathrm{t}$ hitung sebesar 7.937>1.791 (t-tabel) (Peni et al., 2016). Ada analisis 
yang signifikan antara komponen fisik terhadap keterampilan smash, dengan nilai $\mathrm{R}$ sebesar $0.836\left(\mathrm{P}_{\text {value }}<\alpha 0,05\right)$ nilai kontribusi sebesar 69,8\%. Ada hubungan antara kekuatan otot lengan, kelentukan pergelangan tangan dan ekstensor otot punggung dengan kemampuan smash backhand, (Agusniar, 2019). Hasil penelitian lain yang juga memperkuat hasil penelitian ini yaitu penelitian yang melakukan uji Faktorial 2x2 diamana hasilnya menunjukkan bahwa terdapat pengaruh interaksi yang signifikan antara metode latihan dan power otot lengan terhadap peningkatan smash bulutangkis, (Prayadi \& Rachman, 2013). Berdasarkan hasil pengolahan dan analisis data dengan uji statistik, ternyata secara empirik terdapat kontribusi yang berarti antara power otot lengan dan fleksibilitas pergelangan tangan terhadap hasil pukulan smash dalam permainan bulutangkis, (Kusnadi, 2015).

Berdasarkan 4 (empat) hasil penelitian diatas, memperlihatkan signifikansi dari implikasi kemampuan otot lengan dan pemberian latihan untuk meningkatkan kemampuan otot lengan. Kemampuan kerja otot lengan yang maksimal menjadi instrumen yang sangat penting dalam keberhasilan smash dalam bulutangkis. Manfaat dari latihan kekuatan otot lengan terhadap teknik dasar smash tentunya sangat signifikan hal tersebut dapat dilihat dari bagaimana mekanisme kerja smash. Gerakan awal dari dari pelaksanaan pukulan smash adalah bagaimana membangkitan tenaga otot-otot yang menggekan kaki, tubuh, pundak, siku, dan pergerakan tangan (Aji Prasojo \& Yahya, 2017). Untuk menghasilkan pukulan smash yang bermutu dipengaruhi kondisi fisik dan teknik yang dimaksud faktor fisik diantaranya kecepatan dan kekuatan otot lengan. Gerakan pukulan smash lebih banyak didominasi oleh gerakan kekuatan otot tangan dan lengan, (Amatae \& Brilin, 2015).

Apabila seseorang pemain bulutangkis memiliki power otot lengan yang baik, maka pemain tersebut dapat melakukan pukulan smash yang kuat dan cepat sehingga sulit untuk dikembalikan oleh lawan (Kusnadi, 2015). Berdasarkan geraknya, komponen fisik yang menunjang kemampuan smash yakni kekuatan otot lengan. Kemampuan fisik tersebut terutama ditekankan pada bagian tubuh yang memegang peranan penting dalam melakukan pukulan smash, seperti kelentukan, daya ledak dan keseimbangan (Kamaruddin, 2019). Kecepatan rotasi 
dari sendi bahu pada gerakan internal shoulder rotation, sendi lengan gerakan wrist palmar flexion serta sendi lengan bagian atas gerakan forearm supination memberikan kontribusi yang sangat signfikan terhadap kecepatan shuttlecock pada saat melakukan overhead jumping smash dalam permainan bulutangkis, (Rusdiana, 2020).

Sebagaimana variable yang digunakan pada penelitian ini yaitu Latihan Fullover dengan implikasi mengembangkan kemampuan power otot lengan dan disaat bersamaan akan meningkatkan kualitas smash seorang atlet. Secara mendasar pukulan smash sangat terkait dengan kemampuan dan kerja otot-otot besar pada beberapa bagian tubuh, otot lengan dan otot lengan bawah,(Al-Haliq, 2020). Artinya bahwa power otot lengan yang juga dapat dikembangkan melalui latihan Fullover akan sangat mempengaruh hasil pukulan smash, begitupun sebaliknya dengan rendahnya kemampuan power otot lengan akan membuat pukulan smash tidak maksimal. Seorang atlet yang mengalami kelelahan pada kemampuan otot lengan dan otot lengan bawah tidak akan cukup kuat dalam menghasilkan smash yang maksimal, (Zhang, 2020).

Analisis yang lebih mendalam memperlihatkan bahwa pukulan smash sangat membutuhkan power otot lengan dapat diajukan dengan membandingkan dua hasil penelitian yaitu; Hasil analisis Atlet elite dan nonelite menunjukkan bahwa sinergis koordinasi otot selama pukulan smash bulutangkis tidak terlalu kuat dipengaruhi karena perbedaan keterampilan teknik baik itu kelompok atlet elit dan non-elit, (Barnamehei, Ghomsheh, Cherati, \& Pouladian, 2018). Penelitian yang kedua menunjukkan bahwa; Sinergitas otot lengan (rektus abdominis, eksternal oblique (EO), internal oblique/transversus abdominis (IO/TrA), erector spinae, bisep brachii, trisep brachii,flexor carpi radialis, flexor carpi ulnaris, dan fleksor digitorum profundus) pada saat melakukan smash, menunjukkan bahwa untuk pemain berpengalaman (diatas 7 tahun latihan) dan pemain pemula (kurang dari 3 tahun) terdapat dua sinergitas interaksi otot yang bekerja yaitu rektus abdominis dan eksternal oblique (EO), adapun kelebihan pemain yang lebih berpengalaman yaitu koaktivasi IO/TrA dan otot lengan bawah sehingga meningkatkan performa pukulan smash yang dimiliki, (Matsunaga \& Kaneoka, 2018). Kedua hasil penelitian tersebut menunjukkan 
bahwa baik itu kelompok atlit elit dan non-elit bukanlah varibel penentu dari hasil smash yang maksimal namun yang terpenting adalah mensinergikan kemampuan atau kerja otot-otot lengan, dan umumnya kerja atau kinerja tersebut ditemui pada atlet elit atau berpengalaman.

Selanjutnya yang cukup penting untuk diperhatikan dan disikapi adalah pelaksanaan latihan (treatment) yang dilakukan dengan ketentuan Work Form Home (WFH) dapat maksimal dilaksanakan apabila ada komitmen dan keseriusan dari seluruh pihak yang terlibat, adanya disiplin yang tinggi dari atlet yang berlatih, dan kemampuan pelatih dalam menvisualisasikan latihan-latihan yang akan diberikan secara daring. Penelitian dalam masa Pendemic dapat dijalankan dengan sukses tentunya dengan penggunaan serta pengembangan media (elearning, Google Form, dan lain sebagainya), dan komitmen yang tinggi dari semua pihak (Dahlan, Hidayat, \& Syahruddin, 2020).

\section{SIMPULAN}

Dalam masa pandemi Covid 19 sangat menghambat jalannya kegiatan yang sifatnya tatap muka, hal demikian juga berdampak pada jalannya proses pembinaan prestasi cabang olahraga (latihan). Karena sifat latihan yang harus dijalanan secara kontiniu dan sistematis maka tentunya proses latihan tidak dapat berhenti, sehingga penelitian ini berupaya untuk mengimplementasikan latihan Fullover terhadap peningkatan teknik dasar smash atlet UKM Bulutangkis UM Palopo. Hasil penelitian ini memperlihatkan bahwa latihan Fullover memiliki pengaruh yang siginifikan terhadap peningkatan teknik dasar smash atlet UKM Bulutangkis UM Palopo.

\section{DAFTAR RUJUKAN}

Agusniar. (2019). Hubungan Antara Kekuatan Otot Lengan, Kelentukan Pergelangan Tangan Danekstensor Otot Punggung Dengan Kemampuan Smash Backhand Dalam Permainan Bulutangkis Pada Atlet Cemerlang Kota Palu. Jurnal E-JTPEHR, 1(3), 1-13.

Aini, K., \& Kemala, A. (2020). Status Gizi Atlet Cabang Olahraga Atletik DKI Jakarta Masa Covid-19 berdasarkan Antropometri. JUARA: Jurnal Olahraga, 6(1), 12-20. 
Aji Prasojo, D., \& Yahya, A. (2017). Pengaruh Umpan Tetap dan Umpan Berubah terhadap Akurasi Smash dalam Permainan Bulutangkis SMK Penerbangan Singosari. Jurnal Pendidikan. Jasmani, Olahraga Dan Kesehatan), 1(1), 23-29.

AlHaliq, M. (2020). The effect of a training program using speed-specific strength exercises on sensory-motor perception in learning stroke forehand smash in badminton material for students of the Hashemite University. International Journal of Human Movement and Sports Sciences, 8(6), 299-307.

Amatae, E. Y., \& Brilin, A. S. (2015). Pengaruh Latihan Knee Tuck Jump dan Double Leg Hop Progression terhadap Peningkatan Smash Bulutangkis Siswa Kelas X di SMA Negeri 1 Bulutaba. Tadulako Journal Sport Sciences And Physical Education, 3(12), 1-14.

Arikunto, S. (2014). Prosedur Penelitian Suatu Pendekatan Praktik. Jakarta: Rineka Cipta.

Barnamehei, H., Ghomsheh, F. T., Cherati, A. S., \& Pouladian, M. (2018). Upper limb neuromuscular activities and synergies comparison between elite and nonelite athletics in badminton overhead forehand smash. Applied Bionics and Biomechanics, 2018. https://doi.org/10.1155/2018/6067807

Cendra, R. (2018). Hubungan Explosive Power Otot Tungkai terhadap Akurasi Smash Jump Bulutangkis Tim Putra Pembinaan Prestasi Mahasiswa Pendidikan Olahraga Universitas Riau. Jurnal Pendidikan Jasmani Dan Olahraga, 3(1), 69. https://doi.org/10.17509/jpjo.v3i1.10462

Dahlan, F., Hidayat, R., \& Syahruddin, S. (2020). Pengaruh komponen fisik dan motivasi latihan terhadap keterampilan bermain sepakbola. Jurnal Keolahragaan, 8(2), 126-139. https://doi.org/10.21831/jk.v8i2.32833

Hidayat, A. K. (2020). Penerapan Project Based Learning pada Pendidikan Jasmani di Masa Social Distancing Pandemic Covid -19. JUARA: Jurnal Olahraga, 6(1), 1-11.

Kamaruddin, I. (2019). Pengaruh Kemampuan Fisik terhadap Keterampilan Smash dalam Permainan Bulutangkis. SPORTIVE: Journal Of Physical Education, Sport and Recreation, 2(2), 114-127. https://doi.org/10.26858/sportive.v2i2.10949

Kusnadi, N. (2015). Kontribusi Fleksibilitas Pergelangan Tangan dan Power Otot Lengan terhadap Hasil Pukulan Smash dalam Permainan Bulutangkis. Jurnal Multilateral, 14(2), 79-89.

Mahfud, I., \& Gumantan, A. (2020). Survey Of Student Anxiety Levels During The Covid-19 Pandemic. Jp.Jok (Jurnal Pendidikan Jasmani, Olahraga Dan Kesehatan), 4(1), 86-97. https://doi.org/10.33503/jp.jok.v4i1.1103 
10 Irsan Kahar ${ }^{1}$, Firmansyah Dahlan ${ }^{2)}$, Syahruddin ${ }^{3}$.Jp.jok (Jurnal Pendidikan. Jasmani, Olahraga dan Kesehatan).

Matsunaga, N., \& Kaneoka, K. (2018). Comparison of modular control during smash shot between advanced and beginner badminton players. Applied Bionics and Biomechanics, 2018. https://doi.org/10.1155/2018/6592357

Nugraha, P. D., Utama, M. B. R., S, A., \& Sulaiman, A. (2020). Survey Of Students Sport Activity During Covid-19 Pandemic. Jp.Jok (Jurnal Pendidikan Jasmani, Olahraga Dan Kesehatan), 4(1), 11-24.

PB. PBSI. (2006). Buku Pedoman Bulutangkis. Jakarta: PB. PBSI.

Peni, E., Saripin, \& Kristi, A. (2016). Pengaruh Metode Latihan Power Otot Lengan terhadap Kemampuan Smash Bulutangkis pada PB. Mandiri Putra Kota Pekanbaru. Jurnal Online Mahasiswa Fakultas Keguruan Dan Ilmu Pendidikan Universitas Riau (JOM FKIP UNRI), 3(2), 1-10.

Prayadi, H. Y., \& Rachman, H. A. (2013). Pengaruh Metode Latihan dan Power Lengan terhadap Kemampuan Smash Bulutangkis. Jurnal Keolahragaan, 1(3), 63-71.

Rahmat, A. (2014). Upaya Meningkatkan hasil Belajar Pukulan Smash Forehand dalam Permainan Bulutangkis melalui Pembelajaran Lempar Bola atas pada Mahasiswa Kelas A Pagi Semester IV IKIP-PGRI Pontianak. Jurnal Pendidikan Olah Raga, 3(2), 105-113.

Rusdiana, A. (2020). Pengaruh Kelelahan terhadap Perubahan Kinematika Gerak pada saat Overhead Jumping Smash dalam Permainan Bulutangkis. Jurnal SPORTIF: Jurnal Penelitian Pembelajaran, 6(2), 272-287. https://doi.org/https://doi.org/10.29407/js_unpgri.vi.14101

Tahir, M., Mentara, H., \& Sultan Brilin, A. (2018). Pengaruh Latihan Triceps Stretch dan Multiple Jump to box terhadap Kemampuan Smash Forehand dalam Permainan Bulutangkis pada Siswa putra Kelas VII SMP Negeri 4 Toli-Toli. Tadulako Journal Sport Sciences And Physical Education, 6(2), 89-98.

Taufan, A., Dewantara, B., \& Alsaudi. (2016). Pengaruh Strategi Pembelajaran dan Konsep diri terhadap Keterampilan Smash Bulutangkis. Multilateral Jurnal Pendidikan Jasmani Dan Olahraga, 15(1), 10-22. https://doi.org/10.20527/multilateral.v15i1.2480

Zarwan, \& Hardiansyah, S. (2017). Pengaruh Media Video dan Media Chart terhadap Ketepatan Smash Bulutangkis Siswa SD Negeri 52 Kuranji Padang. Jurnal PENJAKORA, 4(1), 51-63. https://doi.org/http://dx.doi.org/10.23887/penjakora.v4i1.11753

Zhang, S. (2020). Effects of fatigue on biomechanics of forehand smash in badminton. Journal of Vibroengineering, 22(8), 1826-1833. https $/ /$ doi.org/10.21595/jve.2020.21467 